\title{
Apoptosis is triggered by melatonin in an in vivo model of ovarian carcinoma
}

\author{
Luiz Gustavo A Chuffa', Michelly S Alves', Marcelo Martinez², \\ Isabel Cristina C Camargo ${ }^{3}$, Patricia F F Pinheiro', Raquel F Domeniconi', \\ Luiz Antonio L Júnior ${ }^{1}$ and Francisco Eduardo Martinez ${ }^{1}$ \\ ${ }^{1}$ Department of Anatomy, Institute of Biosciences of Botucatu, UNESP - Universidade Estadual Paulista, \\ PO Box 18618-970, Rubião Júnior, s/n, Botucatu, São Paulo 510, Brazil \\ ${ }^{2}$ Department of Morphology and Pathology, UFSCar - Universidade Federal de São Carlos, \\ São Carlos, São Paulo 13565-905, Brazil \\ ${ }^{3}$ Department of Biological Sciences, Faculty of Sciences and Letters, UNESP - Universidade Estadual Paulista, Assis, \\ São Paulo 19806-900, Brazil
}

\author{
Correspondence \\ should be addressed \\ to L G A Chuffa \\ Email \\ chuffa@ibb.unesp.br
}

\begin{abstract}
Apoptosis plays an important role in the treatment of cancer, and targeting apoptosis-related molecules in ovarian cancer $(\mathrm{OC})$ is of great therapeutic value. Melatonin (Mel) is an indoleamine displaying several anti-cancer properties and has been reported to modulate apoptosis signaling in multiple tumor subtypes. We investigated $O C$ and the role of Mel therapy on the pro-apoptotic (p53, BAX, caspase-3, and cleaved caspase-3) and anti-apoptotic (Bcl-2 and survivin) proteins in an ethanol (EtOH)-preferring rat model. To induce $O C$, the left ovary was injected directly with a single dose of $100 \mu \mathrm{g}$ 7,12-dimethylbenz(a)anthracene dissolved in $10 \mu \mathrm{l}$ of sesame oil under the bursa. Right ovaries were used as sham-surgery controls. After developing $\mathrm{OC}$, half of the animals received i.p. injections of Mel ( $200 \mu \mathrm{g} / 100 \mathrm{~g} \mathrm{BW}$ per day) for 60 days. Body weight gain, EtOH consumption, and energy intake were unaffected by the treatments. Interestingly, absolute and relative $O C$ masses showed a significant reduction after Mel therapy, regardless of EtOH consumption. To accomplish OC-related apoptosis, we first observed that p53, BAX, caspase-3, and cleaved caspase-3 were downregulated in $\mathrm{OC}$ tissue while $\mathrm{BCl}-2$ and survivin were overexpressed. Notably, Mel therapy and EtOH intake promoted apoptosis along with the upregulation of p53, BAX, and cleaved caspase-3. Fragmentation of DNA observed by TUNEL-positive nuclei was also enhanced following Mel treatment. In addition, $\mathrm{Bcl}-2$ was downregulated by the EtOH intake and lower survivin levels were observed after Mel therapy. Taken together, these results suggest that Mel induce apoptosis in OC cells of EtOH-preferring animals.
\end{abstract}

\author{
Key Words \\ - ovarian cancer \\ - melatonin \\ - pro-apoptotic protein \\ - anti-apoptotic protein
}

Endocrine-Related Cancer (2016) 23, 65-76

\section{Introduction}

Ovarian cancer (OC) is one of the most lethal gynecological malignancies and presents a poor prognosis at the moment of diagnosis $(<50 \%$ with a 5 -year survival rate;
Cannistra 2004). Early-stage OC shows no apparent symptoms, and a lack of a reliable screening tool is yet an unsolved issue (Fallows et al. 2001). OC is presumed 
to arise from lesions involving the ovarian surface epithelium, ovarian inclusion cysts, or even distal fimbrial epithelium (Fallows et al. 2001, Cannistra 2004). In advanced OC, resistance to chemotherapy is a major factor limiting long-term treatment against OC (Fallows et al. 2001), and drug resistance has been recognized to induce pro-tumor activities (Kelly et al. 2006, Chen et al. 2008).

Apoptosis is triggered by a sequence of molecular events dependent on extrinsic and intrinsic signaling factors and is associated with tumor cell survival and chemoresistance to treatments (Wong 2011). Specifically in cancer, there is a loss of balance between cell proliferation and cell death involving different signaling molecules with pro-apoptotic (e.g. BAX, Bak, Bad, caspase-3, and others) or anti-apoptotic (e.g. Bcl-2, Bcl-X, survivin, and others) activities (Reed 1997, Wong 2011). Furthermore, activation or repression of certain genes has been found to promote carcinogenesis by reducing apoptosis in OC cells. For example, downregulation of TP53, a tumor suppressor gene, is linked to cisplatin resistance, tumor development and recurrence, and low survival rate in patients with OC (Li et al. 2013). In addition, caspase-3 expression was decreased or undetectable in OC cells, and higher caspase3 activity is expected to undergo apoptosis in response to anti-cancer therapy (Devarajan et al. 2002). Many Bcl2-positive cells are present in a subgroup of OC, and surprisingly, its absence was not correlated to induction of apoptosis (Zusman et al. 2001). Importantly, the blockade of survivin expression contributes to the anti-tumor activity of chemotherapeutic agents in human OC (Jiang et al. 2013).

We have developed a useful rat model for studying appropriate histological and molecular patterns needed to evaluate new therapeutic compounds to treat OC (Chuffa et al. 2013a). These are ethanol (EtOH)-preferring rats induced intrabursally with 7,12-dimethylbenz(a)anthracene (DMBA; Ferreira et al. 2014, Chuffa et al. 2015). In fact, EtOH intake has a variety of co-carcinogenic effects and is associated with apoptosis in normal and altered tissues in a dose- and time-dependent manner (Zeng et al. 2012, Ferreira et al. 2014).

Melatonin (Mel - N-acetyl-5-methoxytryptamine) is an indoleamine produced by the pineal gland at night (Stehle et al. 2011), with antioxidant, immunomodulatory, and oncostatic properties (Reiter 2004). Mel has been described as a molecule with remarkable pro-apoptotic activity in many tumor types, such as Ehrlich tumor, colorectal, breast, and liver (Cos et al. 2002, Batista et al. 2013, Fan et al. 2013, Hong et al. 2014). Activities of Mel on such tumors include modulation of $\mathrm{BAX}$ and $\mathrm{Bcl}-2$
(Hong et al. 2014), p53 and p21 (Cos et al. 2002), and further regulation of caspase- 3 with the release of cytochrome $c$ (Perdomo et al. 2013). Most reports on the apoptotic effect of Mel to cancer cells are focused on oxidative stress (Rodriguez et al. 2013), and no study was conducted to test the efficacy of Mel therapy on OC regarding the apoptosis signaling molecules. Therefore, the purpose of this study was to investigate the long-term Mel therapy on the apoptosis in an EtOH-preferring rat model bearing OC. To achieve functional balance, pro-apoptotic and anti-apoptotic proteins were analyzed.

\section{Materials and methods}

\section{Animals and experimental design}

Eighty female adult UChB rats, a model of EtOH-preferring rats (50 days old, weighing $200 \mathrm{~g}$ ), were obtained from the Department of Anatomy, Bioscience Institute/Campus of Botucatu, UNESP - Universidade Estadual Paulista. The rats were individually housed in polypropylene cages containing laboratory-grade pine shavings as bedding and maintained under constant room temperature (RT; $\left.23 \pm 1{ }^{\circ} \mathrm{C}\right)$ and lighting conditions $(12 \mathrm{~h}$ light: $12 \mathrm{~h}$ darkness cycle, with the lights switched on at $0600 \mathrm{~h}$ ). Filtered tap water and standard rodent chow (3074 SIF, Purina Ltda., Campinas, SP, Brazil) were provided ad libitum. All animals were divided into two groups $(n=40)$ : EtOH group, in which the rats had access to a $10 \%(\mathrm{v} / \mathrm{v})$ EtOH solution ad libitum (free choice of water or $\mathrm{EtOH})$, and a control group, which was composed of EtOH-naïve rats without access to EtOH. At 65 days of age, they were given a choice between two bottles containing either water or a $10 \%(\mathrm{v} / \mathrm{v}) \mathrm{EtOH}$ solution ad libitum over a period of 15 days. Animals displaying EtOH consumption higher than $2.0 \mathrm{~g}$ of $\mathrm{EtOH} / \mathrm{kg}$ per day (from 4 to $5 \mathrm{~g}$ of $\mathrm{EtOH} / \mathrm{kg}$ per day) were selected to this study according to Chuffa et al. (2011a, 2013b).

After OC development (260 days old), the animals designated to receive Mel (M-5250, Sigma-Aldrich) were administered i.p. doses of $200 \mu \mathrm{g} / 100 \mathrm{~g}$ BW dissolved in $0.04 \mathrm{ml}$ of $95 \% \mathrm{EtOH}$ and then diluted in $0.3 \mathrm{ml}$ of $0.9 \%$ $\mathrm{NaCl}$ (vehicle) at a final concentration of $0.3 \mathrm{mg} / \mathrm{ml}$. The daily injections were administered at night (between 1830 and $1900 \mathrm{~h}$ ) for 60 consecutive days (Chuffa et al. 2011b). This protocol relies on previous works in which long-term Mel therapy was able to reduce tumor size and tumor cell survival.

Finally, the rats were divided into four subgroups $(n=20)$ : OC, composed of DMBA-induced animals that

Published by Bioscientifica Ltd. 
did not consume EtOH; OC+EtOH, composed of DMBAinduced animals that consumed $10 \%$ (v/v) EtOH during ovarian tumor development (OTD); OC+Mel, composed of DMBA-induced animals that received Mel treatment; and $\mathrm{OC}+\mathrm{EtOH}+\mathrm{Mel}$, composed of DMBA-induced animals that consumed $10 \%$ (v/v) EtOH during OTD and received Mel treatment. After all procedures, the females were anesthetized and euthanized by decapitation (during early morning at $0400 \mathrm{~h}$ ) for further sample collection. The present experimental protocol was accepted by the Ethical Committee of the Institute of Bioscience/UNESP (CEEA - permit number: 382).

\section{Ovarian tumor induction}

After selection, all the animals $(n=80)$ were anesthetized using $10 \%$ ketamine $(60 \mathrm{mg} / \mathrm{kg}$, i.p.) and $2 \%$ xylazine $(5 \mathrm{mg} / \mathrm{kg}$, i.p.) during the estrous phase, a $2 \mathrm{~cm}$ incision through the skin and abdominal muscles was performed, and the left ovaries were accessed after grasping the fat pad surrounding the organ. The left ovary was injected under the bursa with a dose of $100 \mu \mathrm{g}$ of DMBA (Sigma-Aldrich) dissolved in $10 \mu \mathrm{l}$ of sesame oil (vehicle) (Hoyer et al. 2009), and was returned intact to the body cavity. Muscle and skin layers were closed using a 3-0 silk suture (Ethicon, Inc., Juarez, Mexico). Control surgery was conducted on the right ovary by administering only the vehicle. Prophylactic antibiotic $\left(10^{5}\right.$ units of benzylpenicillin potassium) was administered i.p. for 2 weeks. Over the next 180 days, tumor development was observed by ultrasonography (size and volume).

\section{Mel levels}

Blood was collected each 15 days from the caudal vein and Mel was extracted from the plasma ( $n=20$ samples/group) using HPLC-grade methanol and separated on columns (Sep-Pak Vac C-18, reverse phase, $12.5 \mathrm{~nm}$; Water Corporation, Milford, MA, USA). Thereafter, $50 \mu \mathrm{l}$ of reconstituted samples were assayed using a Coat-a-count Mel ELISA Kit and immediately read at $405 \mathrm{~nm}$. Intra-assay coefficient of variation was $4 \%$, and all the samples were assayed at the same time in duplicate. The microtiter plates and reagents were provided by IBL International (Hamburg, Germany), and the concentrations of $\mathrm{Mel}$ are presented as $\mathrm{pg} / \mathrm{ml}$.

\section{Immunohistochemistry}

Sections of papillary OC tissue ( $n=10 /$ group) were deparaffinized in xylene and were microwaved
(700-800 W) while immersed in $0.01 \mathrm{M}$ sodium citrate buffer, $\mathrm{pH}$ 6.0, for antigen retrieval. After blocking endogenous peroxidase activity, the tissues were incubated with 3\% BSA for $1 \mathrm{~h}$ to avoid non-specific binding. Then, OC sections were incubated in a humidified chamber overnight at $4{ }^{\circ} \mathrm{C}$ with primary antibodies (Abcam, Cambridge, UK): rabbit monoclonal anti-p53 (1:100), rabbit polyclonal anti-BAX, rabbit monoclonal anticaspase-3 (1:50), rabbit polyclonal anti-Bcl-2 (1:100), and rabbit polyclonal anti-survivin (1:100). After immunoreactions, the slides were washed in TBS-T buffer and incubated with secondary antibody (polymer anti-mouse IgG or anti-rabbit IgG; Dako Cytromation, Carpinteria, CA, USA) at RT for $1 \mathrm{~h}$. Then, the slides were reacted with diaminobenzidine (Sigma-Aldrich) for $5 \mathrm{~min}$. Finally, OC sections were counterstained with hematoxylin. Negative controls were generated by omitting the primary antibody. Immunohistochemistry (IHC) results were analyzed under a Zeiss Axiophot II microscope (Carl Zeiss, Oberkochen, Germany), considering the levels of staining intensity which were scored as absent $(0)$, weak $(+)$, moderate $(++)$, or strong $(+++)$ immunoreactivity. All of the OC-positive cells for p53, BAX, caspase-3, TUNEL, Bcl-2, and survivin were counted on ten random fields $(\times 400)$ considering total tumor cells (data expressed as \%).

\section{Determination of DNA fragmentation by TUNEL assay}

OC tissues were washed with PBS (sodium chloride, potassium chloride, dihydrogen phosphate, and disodium hydrogen phosphate), fixed in $4 \%$ paraformaldehyde for $10 \mathrm{~min}$, and permeabilized with PBS at RT. Cryostat sections $(15 \mu \mathrm{m})$ were microwaved in $10 \mathrm{mM}$ citrate buffer, $\mathrm{pH} 6$, for $5 \mathrm{~min}$, and in the same buffer with $0.1 \%$ Triton $\mathrm{X}-100$ for $5 \mathrm{~min}$ at RT. The DNA strand breaks were labeled with -dUTP using TdT $(=0.5 \mathrm{U} / \mu \mathrm{l})$ according to the manufacturer's protocol. The incorporation of nucleotides into $3^{\prime}-\mathrm{OH}$ end was detected with anti-digoxigenin-fluorescein antibody (Sigma-Aldrich; dilution 1:10). Control tissues were incubated without TdT. Nuclei were stained with 6-diamidino-2-phenylindole (DAPI, $5 \mathrm{~min}$ ) at RT. Immunopositive cells were analyzed using a fluorescence microscope (Zeiss Axiophot II, Oberkochen, Germany) at $40 \times$ magnification (excitation $590 \mathrm{~nm}$ and emission filter $650 \mathrm{~nm}$ ). For DAPI staining was used excitation $365 \mathrm{~nm}$; emission filter $435 \mathrm{~nm}$. The quantification of fluorescence in merged figures was performed using the ImageJ Software (NIH, Bethesda, MA, USA).

Published by Bioscientifica Ltd. 


\section{Cell proliferation}

OC tissues were washed with PBS and fixed in paraformaldehyde for $10 \mathrm{~min}$. Cryostat sections were microwaved in $10 \mathrm{mM}$ citrate buffer, $\mathrm{pH} 6$, for $5 \mathrm{~min}$, and in the same buffer with $0.1 \%$ Triton X-100 for 5 min at RT.

Nonspecific binding sites were blocked with 1\% BSA. Samples were incubated with anti-Ki-67 primary rabbit polyclonal antibody (dilution 1:100, overnight at $4{ }^{\circ} \mathrm{C}$ ) followed by secondary polyclonal anti-rabbit IgG conjugated to FITC $(1: 200$, sc-2012, Santa Cruz Biotechnology, Inc.) for $1 \mathrm{~h}$ at RT. Nuclei were stained with DAPI for $5 \mathrm{~min}$. Primary and secondary antibodies were diluted in blocking buffer ( $1 \%$ BSA). For negative immunolabeling, no primary antibody was added. Immunopositive cells were analyzed using a fluorescence microscope (Zeiss Axiophot II) at $40 \times$ magnification. The quantification of fluorescence in merged images was performed using the ImageJ Software (NIH), and proliferation index was obtained in ten random fields considering Ki-67-positive cells by the total tumor cells (\%).

\section{Immunoblots}

After treatments, ovarian tumors were rapidly removed, and $100 \mathrm{mg}$ tissue samples were frozen in liquid nitrogen and stored at $-80^{\circ} \mathrm{C}$. The tissues were homogenized using RIPA lysis buffer (Pierce Biotechnology, Rockford, IL, USA) supplemented with a cocktail of protease inhibitors. Also, Triton X-100 diluted 1:10 (v/v) were added to the homogenates and samples were placed on dry ice with agitation for $2 \mathrm{~h}$ to improve extraction. Lysates were centrifuged at $21912 \mathrm{~g}$ for $20 \mathrm{~min}$ at $4{ }^{\circ} \mathrm{C}$ to remove insoluble material, and total protein was measured through colorimetric determination. All proteins were dissolved in $1.5 \times$ Laemmli buffer and used for SDS-PAGE (Bio-Rad Laboratories). The protein $(70 \mu \mathrm{g})$ was loaded per well and resolved on preformed $4-12 \%$ acrylamide gradient gels (Amersham Biosciences) using a Tris-glycine running buffer electrophoresis system $(60 \mathrm{~mA}$, fixed for $2 \mathrm{~h})$. Then, the proteins were electro-transferred $(200 \mathrm{~mA}$, fixed for $1.5 \mathrm{~h}$ ) to nitrocellulose membranes in Trisglycine-methanol buffer. Pre-stained standards (Bio-Rad) were used as molecular weight markers. After blocking the membranes with TBS-T solution containing 3\% BSA at RT for $60 \mathrm{~min}$, they were incubated at $4{ }^{\circ} \mathrm{C}$ overnight with the primary antibodies (1:1000 in 1\% BSA): p53, BAX, caspase3 , cleaved caspase-3, Bcl-2, and survivin (Abcam). Subsequently, membranes were washed in TBS-T solution and incubated for $2 \mathrm{~h}$ at RT with rabbit HRP-conjugated secondary antibodies (Sigma-Aldrich; diluted 1:1000 in $1 \%$ BSA). After washing in TBS-T, signals were developed using an ECL detection kit (Thermo Fisher Scientific, Waltham, MA, USA). Immunoreactive bands were calculated from individual blots of ten rats per group using image analysis software (ImageJ Software). $\beta$-actin or $\alpha$-tubulin were used as endogenous positive controls, and results were expressed as mean \pm s.D. Immunoblotting concentrations (\%) were represented as optical densitometry values (band intensity-pixels).

\section{Statistical analysis}

Data are presented as the mean \pm s.D., and the analyses were performed using two-way ANOVA for two independent factors (Mel therapy and EtOH intake). Significant results were subjected to post-hoc analysis using Tukey's test, and statistical significance was set at $P<0.05$. SigmaPlot Version 12.5 Graphing Software was used (Systat Software Inc., San Jose, CA, USA).

\section{Results}

\section{Incidence of $O C$ and survival rates}

Although the cumulative OC incidence was increased from day 140 to 200 after the combination of DMBA with EtOH intake (Fig. 1A), no apparent difference in the OC phenotype was observed following EtOH consumption. To confirm the effect of Mel on this rat model of OC, microscopic analyses were frequently performed, and serous papillary carcinoma was the most common tumor subtype (data not shown). To evaluate the prognostic value of long-term Mel treatment associated or not to EtOH consumption, we first investigated non-treated animals bearing $\mathrm{OC}$, and the cumulative survival following different treatments over the 10 months posttumor induction. OC group was compared with the upper $\mathrm{OC}+\mathrm{Mel}$ revealing a significantly shorter disease-specific survival rate (Fig. 1B). Interestingly, after developing multiple metastasis, $100 \%$ of the $\mathrm{OC}+\mathrm{EtOH}$ females die at 8-month post-tumor induction, and Mel therapy promoted longer survival to these females by about $50 \%$ from 8 to 10 months (Fig. 1B).

\section{Overall nutritional aspects and Mel concentrations}

During the experiments, all of the animals were studied with the same criteria. Briefly, the final body weight, body weight gain, food and EtOH consumption, and energy intake did not vary among the treatments (Table 1). The

Published by Bioscientifica Ltd. 

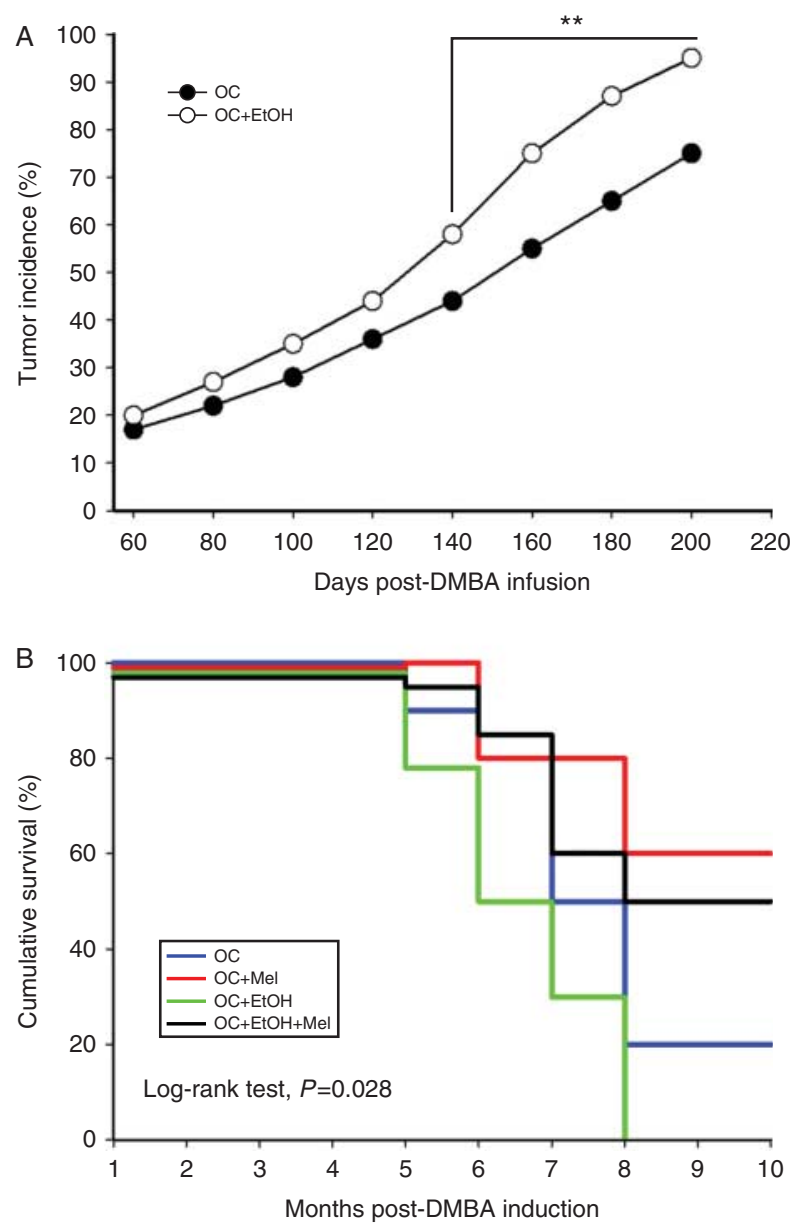

Figure 1

Development of OC and survival. (A) Cumulative incidence (\%) of OC from 60 to 200 days of age in animals receiving EtOH or EtOH + DMBA. The combination of EtOH with DMBA significantly increased the incidence of tumor development from 140 to 200 days post-OC induction, $* * P<0.05$. (B) Kaplan-Meier curve showing animal survival (log-rank test, $P=0.028$ ) through 10 months post-DMBA induction. A full colour version of this figure is available at http://dx.doi.org/10.1530/ERC-15-0463.

absolute and relative OC masses presented significant reductions after Mel treatment in animals consuming or not consuming EtOH. Furthermore, treatment with Mel was able to reduce OC volume in OC + Mel group (Table 1).

To validate the treatment, plasma Mel levels were measured, and efficiently, $\mathrm{OC}+\mathrm{Mel}$ and $\mathrm{OC}+\mathrm{EtOH}+\mathrm{Mel}$ groups exhibited the highest levels of circulating Mel (Table 1).

\section{Mel and EtOH similarly upregulated the expression of pro-apoptotic proteins in OC}

We have investigated the molecular mechanism by which p53 evokes OC cell death, and if BAX is responsible for caspase-3 activation. In response to Mel treatment and EtOH consumption alone, p53 immunostaining and expression were increased (4.8- and 2.7-fold vs OC group respectively) in the epithelium of papillary carcinoma (Table 2 and Fig. 2A, B and E). However, the combination of Mel with EtOH exerted no interference on p53 expression, suggesting that this inhibitory effect may stimulate cell proliferation (Fig. 2A, B and E). Notably, $\mathrm{BAX}$ immunostaining and expression was also higher following Mel and EtOH alone (2.3- and 3.1-fold increased vs OC respectively), while the combination $\mathrm{Mel}+\mathrm{EtOH}$ was unable to alter the protein levels of BAX (Table 2 and Fig. 2A, B and E). Although the caspase-3 immunostaining was intense in the $\mathrm{OC}+\mathrm{Mel}, \mathrm{OC}+\mathrm{EtOH}$, and $\mathrm{OC}+$ $\mathrm{EtOH}+\mathrm{Mel}$ groups (Fig. 2A and Table 2), only Mel alone significantly augmented the levels of caspase-3 (4.3-fold vs OC; Fig. 2B and E) and cleaved caspase-3 (2.7-fold vs OC; Fig. 2C and E), which allow us to consider Mel to be important for effective regulation of downstream targets in OC apoptotic signaling. EtOH consumption alone further increased cleaved caspase- 3 expressions in these cells (Fig. 2C and E).

Immunofluorescence TUNEL staining detected the level and localization of end-labeling of fragmented DNA in OC cells. Mel therapy resulted in increased TUNEL immunolabeling (fluorescence level augmented from $13 \pm$ $4.3 \%$ (OC) to $57 \pm 8.4 \%$ (OC+Mel), Fig. 2D). Interestingly, EtOH intake significantly increased TUNEL immunolabeling (fluorescence level from $13 \pm 4.3 \%$ (OC) to $59 \pm 10.6 \%$ $(\mathrm{OC}+\mathrm{EtOH})$, Fig. 2D), and the combination of Mel with $\mathrm{EtOH}$ was effective in promoting further high fluorescence level $(66 \pm 12.0 \%)$. Unexpectedly, this increase possibly occurred due to another kind of cell death, since both caspase- 3 and activated caspase- 3 were not significantly affected by the $\mathrm{Mel}+\mathrm{EtOH}$ combination. To properly evaluate OC cell turnover, Ki-67 immunolabeling was carried out (Fig. 3A). Despite no significant differences were found in the proliferation rate of OC cells (Fig. 3B), there was a considerable reduction $(P<0.01)$ in cell proliferation/apoptosis ratio following the treatments (Fig. 3C). This low rate of cell turnover favorably argues for extending the pro-apoptotic effect of Mel and EtOH.

\section{Mel and EtOH exerted regulatory effects on the expression of anti-apoptotic proteins in $\mathrm{OC}$}

To investigate the influence of $\mathrm{Mel}$ and $\mathrm{EtOH}$ intake on anti-apoptotic proteins, OC tissues displaying papillary aspect were studied for $\mathrm{Bcl}-2$ and survivin expressions. The immunoreactivity for Bcl-2 was intense in OC and

Published by Bioscientifica Ltd 
Table 1 Nutritional parameters and OC-related characteristics

\begin{tabular}{l} 
Parameters \\
\hline Final body weight $(\mathrm{g})$ \\
Body weight gain $(\%)$ \\
Food consumption $(\mathrm{g} /$ day) \\
EtOH consumption $(\mathrm{ml} / 100 \mathrm{~g}$ per day) \\
Energy intake $(\mathrm{kcal} / \mathrm{day})$ food + EtOH \\
OC masses ${ }^{\mathrm{a}}(\mathrm{g})$ \\
Relative OC masses ${ }^{\mathrm{a}}(\mathrm{g} / 100 \mathrm{~g} \mathrm{BW})$ \\
OC volume $\left(\mathrm{cm}^{3}\right)$ \\
Plasma Mel levels $(\mathrm{pg} / \mathrm{ml})$
\end{tabular}

\begin{tabular}{c}
\hline \\
\hline OC \\
\hline $260 \pm 9.2$ \\
$30 \pm 4.2$ \\
$14.31 \pm 0.46$ \\
- \\
$43.66 \pm 4.17$ \\
$0.24 \pm 0.04$ \\
$0.10 \pm 0.03$ \\
$9.3 \pm 2.1$ \\
$26.34 \pm 6.7$
\end{tabular}

Values are expressed as the mean \pm s.D., $n=20 /$ group. ${ }^{*}{ }^{\dagger} P<0.05$ vs $\mathrm{OC}$ and $\mathrm{OC}+\mathrm{EtOH}$ groups respectively.

${ }^{a}$ The left ovary that was chemically induced with DMBA. Two-way ANOVA complemented by Tukey's test.

drastically decreased along with the treatments (Fig. 4A); however, Bcl-2 protein levels were only significantly downregulated in the $\mathrm{OC}+\mathrm{EtOH}$ group (1.38-fold reduced vs OC, Fig. 4B and C). In addition, higher levels of survivin were present in the cytoplasm of OC cells, and they were gradually decreased over the treatments (Fig. 4A). Importantly, Mel therapy and EtOH alone efficiently reduced the survivin expressions (1.33- and 1.56-fold vs OC respectively, Fig. 4B and C). Lastly, Fig. 4D illustrates a possible scheme by which Mel therapy or EtOH intake may interact positively or negatively with the apoptotic proteins in the OC cells.

\section{Mel and EtOH significantly alter the number of positive OC cells related to apoptosis}

Reinforcing our data, total number of immunolabeled positive cells was counted to identify a real effect of treatments and tumor tissue response. Importantly, the number of p53, caspase-3, and TUNEL-positive cells were significantly higher following the treatments. In addition, BAX-positive cells were higher in $\mathrm{OC}+\mathrm{Mel}$ and $\mathrm{OC}+$ EtOH groups compared with OC (Fig. 5). Conversely, the number of Bcl-2-positive tumor cells was dramatically reduced by either $\mathrm{Mel}$ or $\mathrm{EtOH}$ and $\mathrm{Mel}+\mathrm{EtOH}$ combination, and only Mel therapy was able to reduce the number of survivin-positive cells (Fig. 5).

\section{Discussion}

We have reported that Mel therapy efficiently reduced OC masses (size and volume) as well as the incidence of papillary carcinomas (Chuffa et al. 2013a). In the present study, we focused to the apoptotic mechanism of the OC cells after Mel therapy in an EtOH-preferring rat model.
To support the effectiveness of treatment, plasma Mel was measured throughout the experiment, and circulating Mel was higher in the $\mathrm{OC}+\mathrm{Mel}$ and $\mathrm{OC}+\mathrm{EtOH}+\mathrm{Mel}$ groups as compared with their controls. Collectively, this study demonstrated that either Mel or EtOH intake positively regulated the expression of $\mathrm{p} 53, \mathrm{BAX}$, and cleaved caspase3 , and downregulated survivin in papillary OC cells. Furthermore, despite addition of EtOH was effective to promote apoptosis, we observed an increased tumor incidence and a severe reduced survival rate in these animals. Owing to its co-carcinogenic activity, EtOH has already been shown to potentiate OC incidence (Chuffa et al. 2013a,b). However, after OC development, the deleterious effects of EtOH leading animals to experience low survival rate may occur by other systemic mechanism(s).

Being a selective process, apoptosis is important in both physiological and pathological conditions. Mutations of the TP53 gene are the most common molecular alterations in human cancer and in OC are

Table 2 Scoring of IHC of OC cells

\begin{tabular}{|c|c|c|c|c|}
\hline \multirow[b]{2}{*}{ Proteins } & \multicolumn{4}{|c|}{ Treatments } \\
\hline & OC & $\mathrm{OC}+\mathrm{Mel}$ & $\mathrm{OC}+\mathrm{EtOH}$ & $\mathrm{OC}+\mathrm{EtOH}+\mathrm{Mel}$ \\
\hline p53 & 0 & ++ & ++ & + \\
\hline BAX & 0 & ++ & +++ & 0 \\
\hline Caspase-3 & + & +++ & +++ & +++ \\
\hline TUNEL & $0 /+$ & $++I+++$ & $++I+++$ & $++I+++$ \\
\hline Ki-67 & +++ & $++/+++$ & $++I+++$ & $++I+++$ \\
\hline $\mathrm{Bcl}-2$ & ++ & + & + & $0 /+$ \\
\hline Survivin & ++ & $+I++$ & + & + \\
\hline
\end{tabular}

Intensity of $\mathrm{OC}$ staining was analyzed by pathologist visual scoring as 0 (no staining), + (weak staining), ++ (moderate staining), or +++ (strong staining). $n=10$ animals/group. Five selected OC sections were analyzed per animal.

Published by Bioscientifica Ltd. 
A

OC

$\mathrm{OC}+\mathrm{Mel}$ $\mathrm{OC}+\mathrm{EtOH}$ $\mathrm{OC}+\mathrm{EtOH}+\mathrm{Mel}$

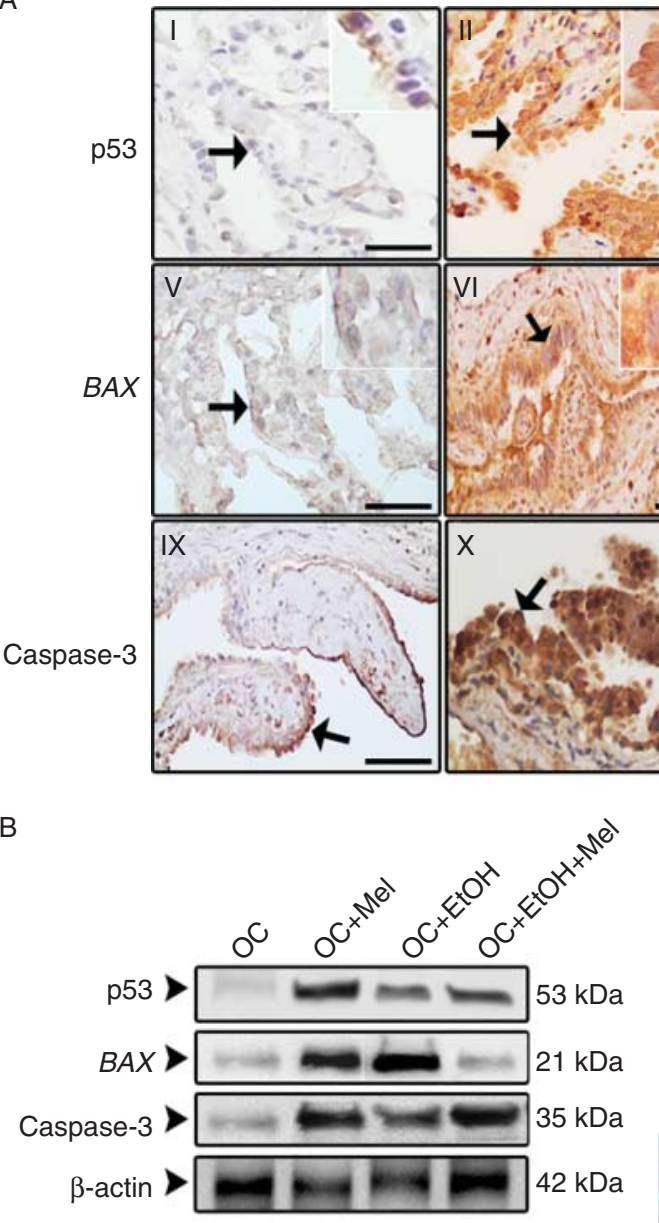

c
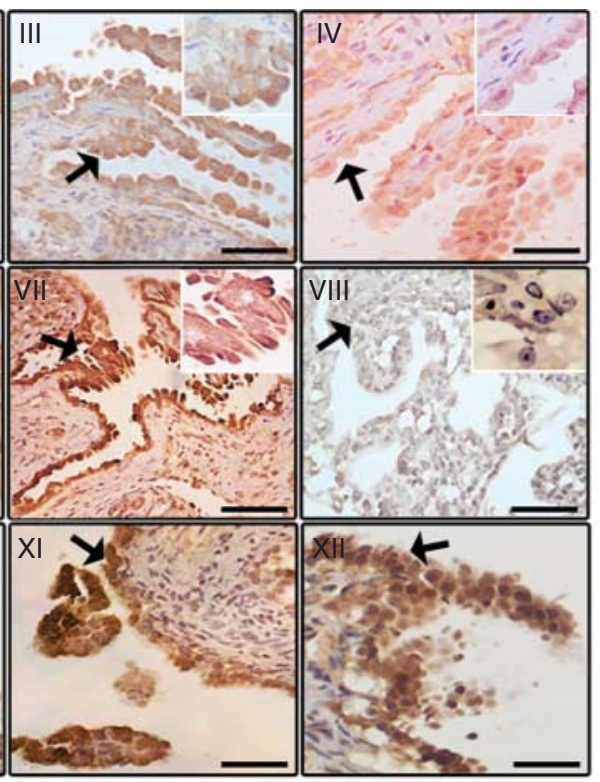

B

$\mathrm{E}$

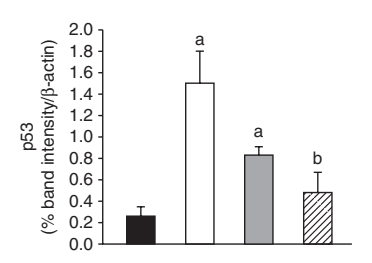

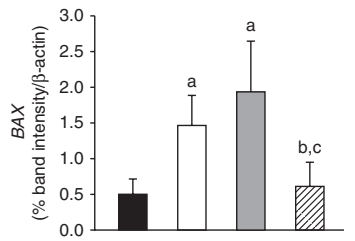
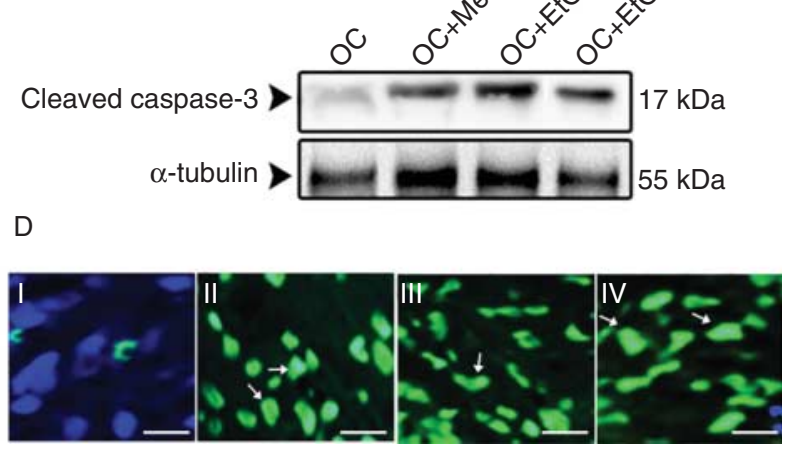

D

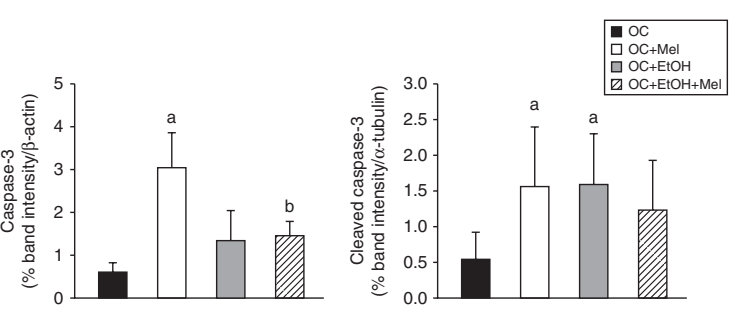

\section{Figure 2}

Immunohistochemical/fluorescence localization and western blot analysis of p53, BAX, caspase-3, and cleaved caspase-3 in serous papillary OC. (A) The immunoreaction of $\mathrm{p} 53$ and BAX was intense in the surface epithelium of the $\mathrm{OC}+\mathrm{Mel}(\mathrm{II}$ and $\mathrm{VI}$ ) and $\mathrm{OC}+\mathrm{EtOH}$ (III and VII) groups (arrows), but not in the stroma. Absence of $\mathrm{p} 53$ and BAX reactions was observed in the $O C$ ( $I$ and $V$ ) group (arrow), while a weak $p 53$ reaction appeared in the epithelium of the $\mathrm{OC}+\mathrm{EtOH}+\mathrm{Mel}$ (IV) group (arrow). A weak caspase-3 reaction was notable in the epithelium of the $O C$ (IX), in contrast to a high immunostaining in the $\mathrm{OC}+\mathrm{Mel}(\mathrm{X}), \mathrm{OC}+\mathrm{EtOH}(\mathrm{XI})$, and $\mathrm{OC}+\mathrm{EtOH}+\mathrm{Mel}(\mathrm{XII})$ groups (arrow). Bar $=20 \mu \mathrm{m}$. Negative controls were used. (B and $C)$ Representative profiles of extracts ( $70 \mu \mathrm{g}$ protein) pooled from ten samples per group. Extracts obtained from individual animals were used for densitometric analysis of the p53, BAX, caspase-3, and cleaved caspase-3 levels following normalization to the $\beta$-actin or $\alpha$-tubulin. (D) Merged images of the TUNEL immunofluorescence and DAPI nuclear staining in OC (I), OC+ Mel (II), OC+ EtOH (III), and OC+EtOH+ Mel (IV); details of the DNA fragmentation (Alexa Fluor 488 , bar $=10 \mu \mathrm{m}$ ). (E) Analysis of relative optical density of the blots. All results are expressed as the mean \pm s.D. $(n=10) .{ }^{\mathrm{a}} P<0.05$ vs OC; ${ }^{\mathrm{b}} P<0.05$ vs $\mathrm{OC}+\mathrm{Mel}$; and ${ }^{C} P<0.05$ vs $\mathrm{OC}+\mathrm{EtOH}$. A full colour version of this figure is available at http://dx.doi.org/10.1530/ERC-15-0463.

Published by Bioscientifica Ltd. 

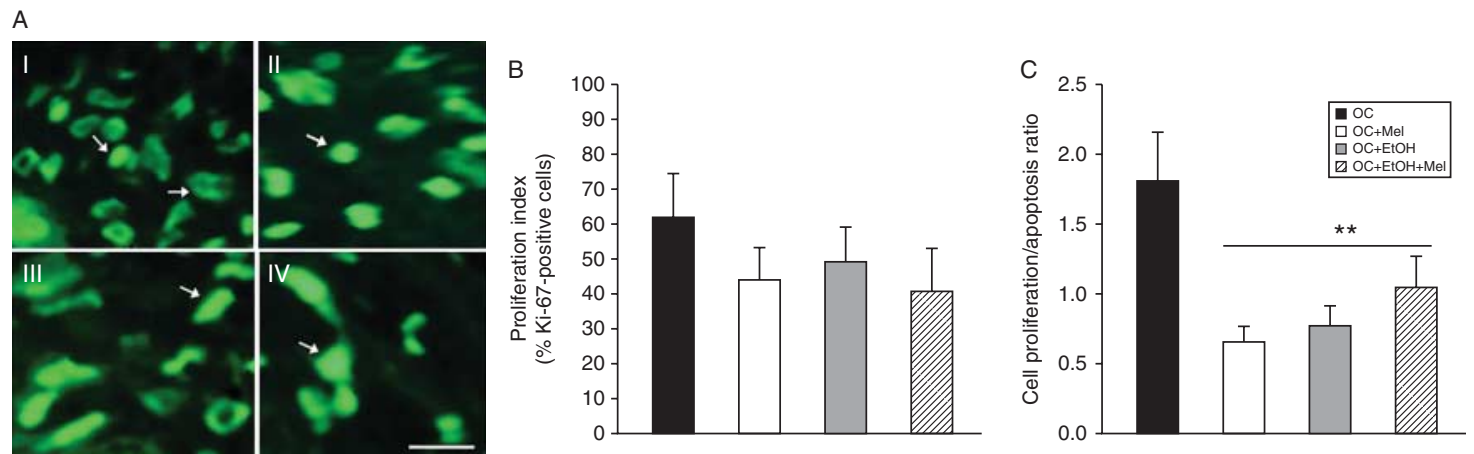

\section{Figure 3}

Proliferative index analysis in serous papillary OC. (A) Merged images of the $\mathrm{Ki}-67$ immunofluorescence and DAPI staining in OC (I), OC+ Mel (II), OC+ $\mathrm{EtOH}$ (III), and $\mathrm{OC}+\mathrm{EtOH}+\mathrm{Mel}$ (IV); white arrow: nuclear staining (Alexa Fluor, bar $=10 \mu \mathrm{m}$ ). (B) Percentage of Ki-67-positive cells counted in

associated to an early event in high-grade serous carcinoma with ubiquitous occurrence (Salani et al. 2008, Ahmed et al. 2010). Recent data have indicated that complete absence of p53 immunolabeling is associated with poor-prognosis-related mutation in OC (Yemelyanova et al. 2011). Notably, we found a significant overexpression of p53 and BAX in papillary epithelium following either Mel therapy or EtOH intake, but not after their combination. In fact, the cytotoxic effect of Mel in tumor cells is counter-intuitive, since high levels of Mel are related to protection of normal cells and inhibition of cell proliferation (Martín et al. 2006, García-Navarro et al. 2007). The increase in the levels and activity of p53 was accompanied by activation of other apoptosis-related signaling pathways in liver cancer cells and LNCaP androgen-dependent prostate cancer cells treated with 1 mM Mel (Martín-Renedo et al. 2008, Joo \& Yoo 2009). Nuclear accumulation of the p53 leads to altered transcription of death-susceptible p53-responsive genes (e.g. Bax), while concomitantly suppress the expression of the Bcl-2 survival gene (Krajewski et al. 1994). In our study, the effect of Mel combined with EtOH inhibited the levels of pro-apoptotic p53 and BAX levels.

According to Ferreira et al. (2014), Mel is able to modulate tumor development and metastasis, thus attenuating the signaling pathway related to OC cell survival. Similarly, our findings demonstrated that Mel promoted a reduction in OC volume and masses displaying pro-apoptotic and anti-proliferative actions on the OC development. In breast cancer cell line, Mel significantly increased the expression of p21WAF1 mediated by p53, resulting in the imbalance of proliferation/apoptosis ratio different areas of OC. (C) Relation between Ki-67-positive cells and TUNELpositive cells. ${ }^{*} P<0.01$ vs OC. A full colour version of this figure is available at http://dx.doi.org/10.1530/ERC-15-0463.

(Mediavilla et al. 1999). Mel is an undisputed agent capable of modulating the clock genes expression (Blask et al. 2011). Alternatively, differential expression of clock genes (e.g. PER1 and PER2) may exert influences on cancer cell proliferation and growth, as evidenced in breast cancer (Yang et al. 2009) and other malignancies (Wood et al. 2009).

Caspases represent one important player in the initiation and execution of apoptosis, and is a consensus that low levels or impairment in effector caspase function may decrease apoptosis and facilitate carcinogenesis (Wong 2011). Devarajan et al. (2002) reported that caspases-3 mRNA levels in commercially available total samples from breast and cervical tumors were undetectable or substantially decreased in ovarian tumors. We observed a reduced expression of total and cleavedcaspase- 3 in OC cells, and conversely, Mel therapy over the 60 days significantly increased total caspase- 3 expressions. Furthermore, nuclear active caspase-3 was upregulated by either $\mathrm{Mel}$ or EtOH intake. These findings are in accordance to Kim et al. (2012), which Mel treatment resulted in the sub-G1 DNA contents and TUNEL-positive cells in OC cell line (SK-OV-3), and combined treatment of Mel with cisplatin increased the cleavage of caspase-3 and poly-(ADP-ribose) polymerase. Importantly, fragmentation of DNA evidenced by the TUNEL-positive cell immunofluorescence was higher in the $\mathrm{OC}+\mathrm{Mel}, \mathrm{OC}+\mathrm{EtOH}$, and $\mathrm{OC}+\mathrm{EtOH}+\mathrm{Mel}$, thereby proving that either $\mathrm{Mel}$ or $\mathrm{EtOH}$ are able to undergo apoptosis in OC cells of EtOH-preferring rats. Like a double-edged sword, defects or abnormalities in apoptotic pathways may be an interesting target of cancer therapy

Published by Bioscientifica Ltd 
A
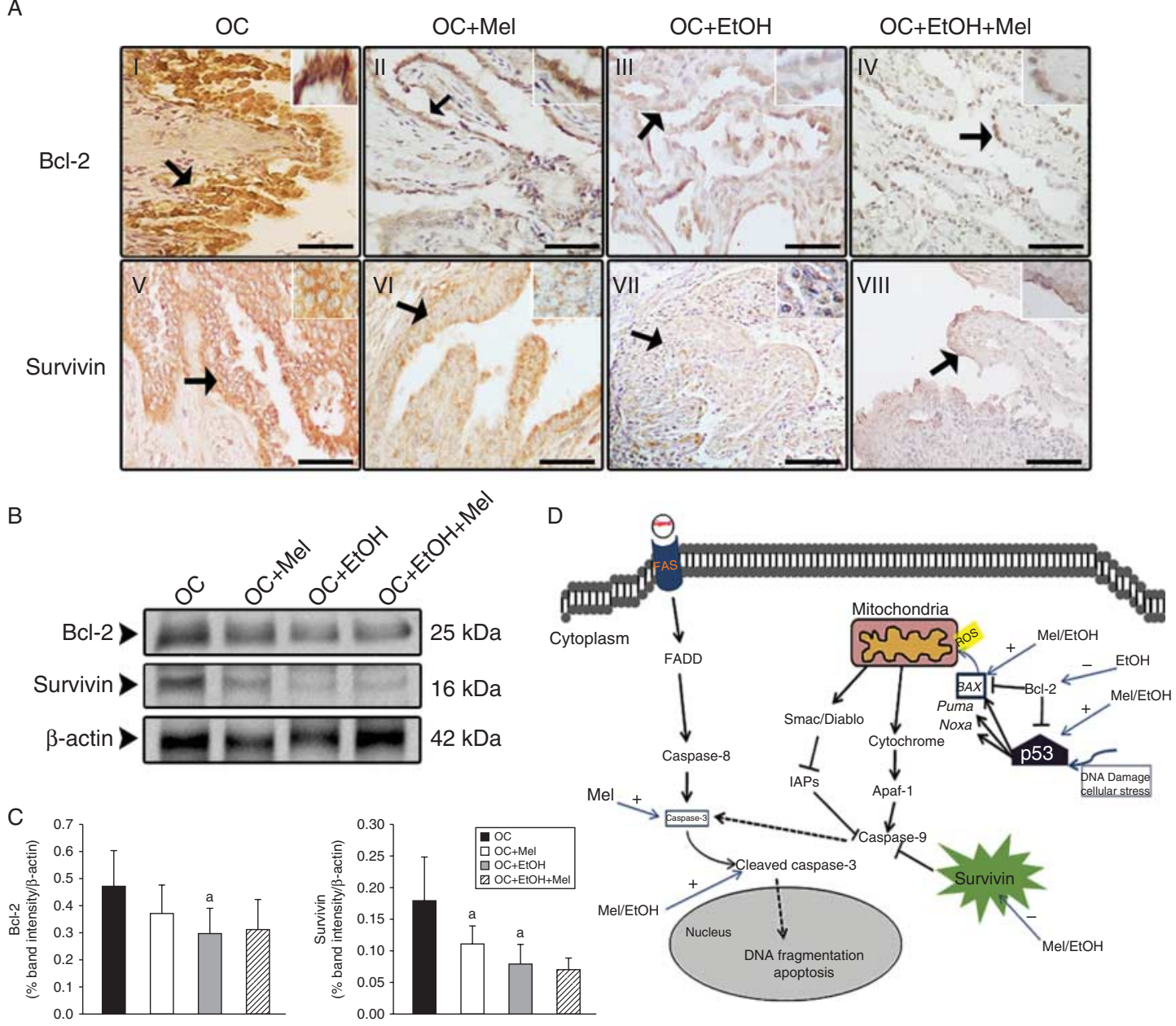

$\mathrm{Mel} / \mathrm{E} \mathrm{OH}$

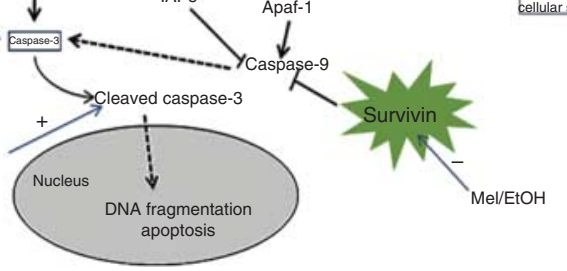

\section{Figure 4}

Immunohistochemical localization and western blot analysis of $\mathrm{Bcl}-2$ and survivin in serous papillary OC. (A) The immunoreaction of $\mathrm{Bcl}-2$ was moderate in the $\mathrm{OC}(\mathrm{I})$ while a weak reaction was observed in the $\mathrm{OC}+\mathrm{Mel}$ (II), $\mathrm{OC}+\mathrm{EtOH}(\mathrm{III})$, and $\mathrm{OC}+\mathrm{EtOH}+\mathrm{Mel}$ (IV) animals (arrow). Immunoreaction of survivin was moderate in the surface epithelium of the $O C(V)$ and a weak reaction was notable in the $\mathrm{OC}+\mathrm{Mel}(\mathrm{VI}), \mathrm{OC}+\mathrm{EtOH}(\mathrm{VII})$, and $\mathrm{OC}+\mathrm{EtOH}+\mathrm{Mel}(\mathrm{VIII})$ groups (arrow). Bar $=20 \mu \mathrm{m}$. Negative controls were used. (B) Representative $\mathrm{Bcl}-2$ and survivin profiles of extracts $(70 \mu \mathrm{g}$ protein) pooled from ten samples per group. (C) Extracts obtained from individual animals were used for densitometric analysis of the proteins following normalization to house-keeping genes ( $\beta$-actin). All results are expressed as the mean \pm s.D. $(n=10)$. ${ }^{a} P<0.05$ vs OC. (D) Schematic

(Wong 2011). New adjuvant drugs or treatment strategies that can restore the apoptotic signaling have a potential to eliminate cancer cells.

Targeting Bcl-2 and other anti-apoptotic proteins or silencing the upregulated anti-apoptotic proteins or genes are also a promising approach for the treatment of OC. In our study, only EtOH-consuming animals bearing OC had a significant reduction of Bcl-2 levels. Although our results were unable to demonstrate a real effect of Mel in the representation of the intrinsic and extrinsic apoptosis signaling pathway leading to the final DNA fragmentation in OC cell. p53 is activated in the presence of DNA damage or oxidative stress stimuli, and BAX heterodimerizes with $\mathrm{Bcl}-2$ to increase the opening of mitochondrial voltagedependent channel, which leads to the release of cytochrome c. After binding to Apaf-1, caspase- 9 is activated, and the subsequent caspase cascade makes the cell to undergo apoptosis. p53, BAX, and cleaved caspase-3 are upregulated and survivin is downregulated by either Mel or $\mathrm{EtOH}$. Bcl-2 was downregulated by the EtOH intake, and Mel therapy positively regulated caspase- 3 expression in $\mathrm{OC}$ tissue. A full colour version of this figure is available at http://dx.doi.org/10.1530/ERC-15-0463.

downregulation of Bcl-2, there was a profound reduction in survivin expression following either Mel therapy or EtOH intake. It has been extensively studied the role of high concentrations of Mel in determining the proapoptotic actions related to early oxidative stress in tumor cells (Trubiani et al. 2005, Rubio et al. 2007). For example, Trubiani et al. (2005) described activation of caspase- 3 and cytochrome $c$, and a decrease in the levels of Bcl-2 after treatment with $2 \mathrm{mM}$ Mel in lymphoma cell

Published by Bioscientifica Ltd 

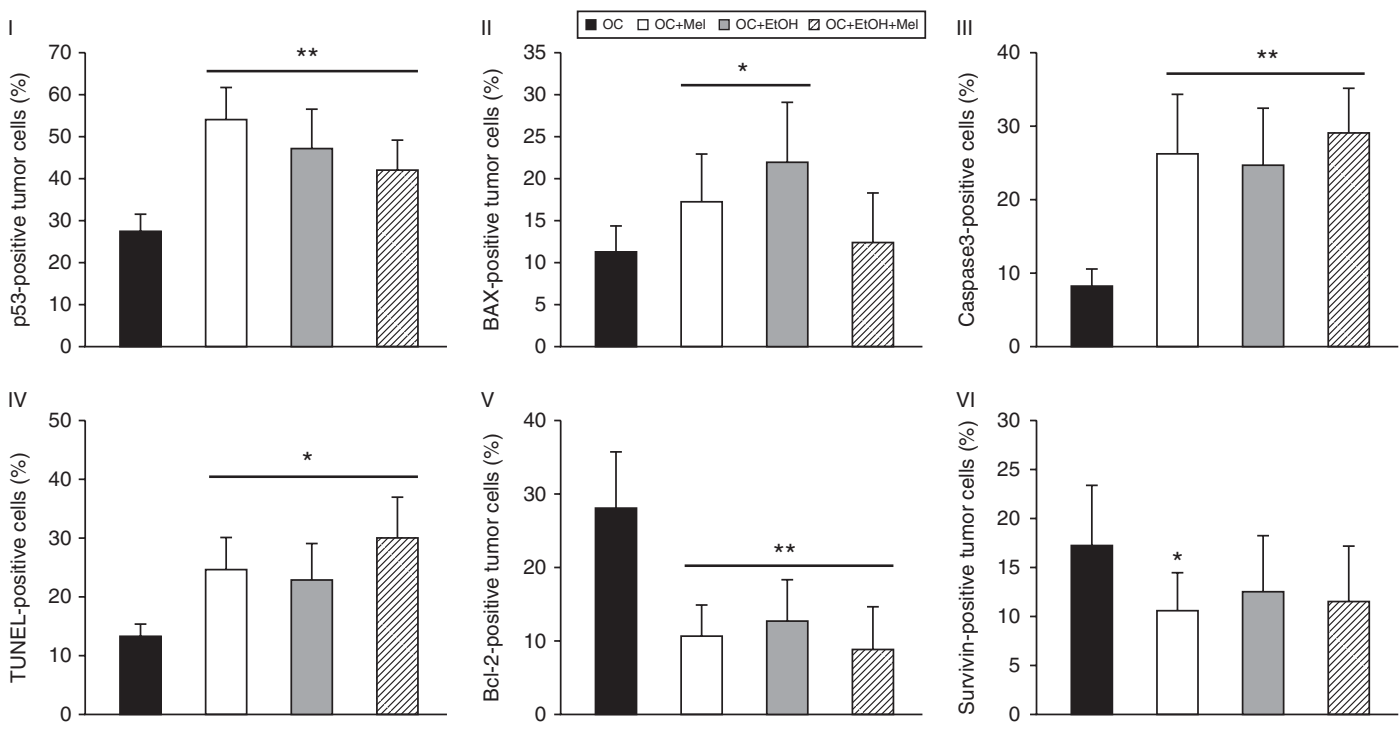

\section{Figure 5}

Number of positive immunostained cells by the total tumor cells (\%) counted in different areas (ten sections per animal per group). p53-positive cells (I), BAX-positive cells (II), caspase-3-positive cells (III), TUNEL-positive

line. Acute myeloid leukemia HL60 cells also exhibit an increase in activated caspase- 9 and caspase-3, and in the levels of BAX and cytochrome $c$ released to the cytoplasm, as well as a reduction in Bcl-2 levels (Rubio et al. 2007). Although we did not explore any parameter of the extrinsic pathway, these data strongly support our results given that high and prolonged treatment with Mel activates the intrinsic apoptotic pathway in OC cells. More specifically, the relationship between apoptosis and reactive oxygen species formation following Mel therapy will be further investigated in other studies.

Survivin is a bifunctional protein capable of regulating cell proliferation and suppressing apoptotic cell death (O'Driscoll et al. 2003). Survivin overexpression in tumor and normal cells shows inhibition of cell death induced by many apoptotic stimuli, including Fas, BAX, caspases, and anti-cancer drugs. Notably, OC samples in our study showed higher expression of cytoplasmic survivin, and surprisingly, Mel therapy efficiently reduced their levels. Recently, Mel therapy significantly inhibited the growth of human hepatocellular carcinoma and induced apoptosis along with the downregulation of survivin and XIAP (Fan et al. 2013). However, the exact mechanism(s) by which Mel modulates survivin remain inconclusive. As a number of reports elicited survivin and other inhibitors of apoptosis to have poor prognosis in various cancer types, targeting these anti-apoptotic molecules may provide a therapeutic potential for the treatment of OC. cells (IV), BCl-2-positive cells (V), and survivin-positive cells (VI). All results are expressed as the mean \pm s.D. $(n=10) .{ }^{*} P<0.05$ and $* * P<0.01$ vs OC group.

In summary, Mel therapy efficiently reduced OC by altering both volume and masses, while leading to apoptosis of the OC cells. Importantly, either Mel or EtOH intake promoted an increase of p53, BAX, and cleaved caspase- 3 with concomitant DNA fragmentation in OC tissue, thus acting as a positive regulator of proapoptotic proteins. Conversely, Mel exerted a negative regulation upon anti-apoptotic proteins which suggest Mel to be an inductor of apoptosis in OC of EtOHpreferring rats. Although additional studies are needed, Mel could be used as an adjuvant agent to promote apoptosis in OC tissue.

Declaration of interest

The authors declare that there is no conflict of interest that could be perceived as prejudicing the impartiality of the research reported.

\section{Funding}

We would like to give a special thanks to FAPESP (Fundação de Amparo à Pesquisa do Estado de São Paulo, Proc. 2014/05196-3, 2013/02466-7) by providing financial support.

\section{Author contribution statement}

L G A Chuffa, F E Martinez, and M S Alves: collected and analyzed the data, drafted the manuscript, and conceived the main idea of the study. M Martinez, P F F Pinheiro, L A L Júnior, R F Domeniconi, and I C C Camargo: participated in the acquisition of data and in the design and intellectual

Published by Bioscientifica Ltd. 
conception of the study. All authors performed the statistical analysis and approved the final version of the manuscript.

\section{Acknowledgements}

We are grateful to Mr Wanderley Thiago da Silva and Mr Gelson Rodriguez from Department of Anatomy, IBB/UNESP, Botucatu-SP, for excellent technical support.

\section{References}

Ahmed AA, Etemadmoghadam D, Temple J, Lynch AG, Riad M, Sharma R, Stewart C, Fereday S, Caldas C, Defazio A et al. 2010 Driver mutations in TP53 are ubiquitous in high grade serous carcinoma of the ovary. Journal of Pathology 221 49-56. (doi:10.1002/path.2696)

Batista AP, Silva TG, Teixeira AA, Medeiros PL, Teixeira VW, Alves LC \& Santos FA 2013 Melatonin effect on the ultrastructure of Ehrlich ascites tumor cells, lifetime and hispathology in swiss mice. Life Sciences 93 882-888. (doi:10.1016/j.lfs.2013.10.012)

Blask DE, Hill SM, Dauchy RT, Xiang S, Yuan L, Duplessis T, Mao L, Dauchy E \& Sauer LA 2011 Circadian regulation of molecular, dietary, and metabolic signaling mechanisms of human breast cancer growth by the nocturnal melatonin signal and the consequences of its disruption by light at night. Journal of Pineal Research 51 259-269. (doi:10.1111/j.1600-079X.2011.00888.x)

Cannistra SA 2004 Cancer of the ovary. New England Journal of Medicine $\mathbf{3 5 1}$ 2519-2565. (doi:10.1056/NEJMra041842)

Chen R, Alvero AB, Silasi DA, Steffensen KD \& Mor G 2008 Cancers take their Toll - the function and regulation of Toll-like receptors in cancer cells. Oncogene 27 225-233. (doi:10.1038/sj.onc.1210907)

Chuffa LG, Seiva FR, Fávaro WJ, Teixeira GR, Amorim JP, Mendes LO, Fioruci BA, Pinheiro PF, Fernandes AA, Franci JA et al. 2011 a Melatonin reduces $\mathrm{LH}, 17 \beta$-estradiol and induces differential regulation of sex steroid receptors in reproductive tissues during rat ovulation. Reproductive Biology and Endocrinology 9 108. (doi:10.1186/1477-7827-9-108)

Chuffa LG, Amorim JP, Teixeira GR, Mendes LO, Fioruci BA, Pinheiro PF, Seiva FR, Novelli EL, Mello Júnior W, Martinez M et al. 2011 b Long-term melatonin treatment reduces ovarian mass and enhances tissue antioxidant defenses during ovulation in the rat. Brazilian Journal of Medical and Biological Research 44 217-223. (doi:10.1590/S0100879X2011007500018)

Chuffa LG, Fioruci-Fontanelli BA, Mendes LO, Fávaro WJ, Pinheiro PF, Martinez M \& Martinez FE 2013a Characterization of chemically induce ovarian carcinomas in an ethanol-preferring rat model: influence of long-term melatonin treatment. PLOS ONE 8 e81676. (doi:10.1371/journal.pone.0081676)

Chuffa LG, Seiva FR, Fávaro WJ, Amorim JP, Teixeira GR, Mendes LO, Fioruci-Fontanelli BA, Pinheiro PF, Martinez M \& Martinez FE $2013 b$ Melatonin and ethanol intake exert opposite effects on circulating estradiol and progesterone and differentially regulate sex steroid receptors in the ovaries, oviducts, and uteri of adult rats. Reproductive Toxicology 39 40-49. (doi:10.1016/j.reprotox.2013.04.001)

Chuffa LG, Fioruci-Fontanelli BA, Mendes LO, Ferreira Seiva FR, Martinez M, Fávaro WJ, Domeniconi RF, Pinheiro PF, Delazari Dos Santos L \& Martinez FE 2015 Melatonin attenuates the TLR4-mediated inflammatory response through MyD88- and TRIF-dependent signaling pathways in an in vivo model of ovarian cancer. BMC Cancer 1534. (doi:10.1186/s12885-015-1032-4)

Cos S, Mediavilla MD, Fernández R, González-Lamuño D \& Sánchez-Barceló EJ 2002 Does melatonin induce apoptosis in MCF-7 human breast cancer cells in vitro? Journal of Pineal Research 32 90-96. (doi:10.1034/j.1600-079x.2002.1821.x)
Devarajan E, Sahin AA, Chen JS, Krishnamurthy RR, Aggarwal N, Brun AM, Sapino A, Zhang F, Sharma D, Yang XH et al. 2002 Downregulation of caspase 3 in breast cancer: a possible mechanism for chemoresistance. Oncogene 21 8843-8851. (doi:10.1038/sj.onc.1206044)

Fallows S, Price J, Atkinson RJ, Johnston PG, Hickey I \& Russell SE 2001 P53 mutation does not affect prognosis in ovarian epithelial malignancies. Journal of Pathology 194 68-75. (doi:10.1002/path.857)

Fan L, Sun G, Ma T, Zhong F \& Wei W 2013 Melatonin overcomes apoptosis resistance in human hepatocellular carcinoma by targeting survivin and XIAP. Journal of Pineal Research 55 174-185. (doi:10.1111/ jpi.12060)

Ferreira GM, Martinez M, Camargo IC, Domeniconi RF, Martinez FE \& Chuffa LG 2014 Melatonin attenuates Her-2, p38 MAPK, p-AKT and mTOR levels in ovarian carcinoma of ethanol-preferring rats. Journal of Cancer 5 728-735. (doi:10.7150/jca.10196)

García-Navarro A, González-Puga C, Escames G, López LC, López A, LópezCantarero M, Camacho E, Espinosa A, Gallo MA \& Acuña-Castroviejo D 2007 Cellular mechanisms involved in the melatonin inhibition of HT-29 human colon cancer cell proliferation in culture. Journal of Pineal Research 43 195-205. (doi:10.1111/j.1600-079X.2007.00463.X)

Hong Y, Won J, Lee Y, Lee S, Park K, Chang KT \& Hong Y 2014 Melatonin treatment induces interplay of apoptosis, autophagy, and senescence in human colorectal cancer cells. Journal of Pineal Research 56 264-274. (doi:10.1111/jpi.12119)

Hoyer PB, Davis JR, Bedrnicek JB, Marion SL, Christian PJ, Barton JK \& Brewer MA 2009 Ovarian neoplasm development by 7,12-dimethylbenz $[a]$ anthracene (DMBA) in a chemically-induced rat model of ovarian failure. Gynecologic Oncology 112 610-615. (doi:10.1016/ j.ygyno.2008.12.013)

Jiang L, Luo RY, Yang J \& Cheng YX 2013 Knockdown of contributes to antitumor activity in cisplatin-resistant ovarian cancer cells. Molecular Medicine Reports 7 425-430. (doi:10.3892/mmr.2012.1216)

Joo SS \& Yoo YM 2009 Melatonin induces apoptotic death in LNCaP cells via p38 and JNK pathways: therapeutic implications for prostate cancer. Journal of Pineal Research 47 8-14. (doi:10.1111/j.1600-079X.2009. 00682.x)

Kelly MG, Alvero AB, Chen R, Silasi DA, Abrahams VM, Chan S, Visintin I, Rutherford T \& Mor G 2006 TLR-4 signaling promotes tumor growth and paclitaxel chemoresistance in ovarian cancer. Cancer Research $\mathbf{6 6}$ 3859-3868. (doi:10.1158/0008-5472.CAN-05-3948)

Kim JH, Jeong SJ, Kim B, Yun SM, Choi do Y \& Kim SH 2012 Melatonin synergistically enhances cisplatin-induced apoptosis via the dephosphorylation of ERK/p90 ribosomal S6 kinase/heat shock protein 27 in SK-OV-3 cells. Journal of Pineal Research 52 244-252. (doi:10.1111/ j.1600-079X.2011.00935.x)

Krajewski S, Krajewska M, Shabaik A, Miyashita T, Wang HG \& Reed JC 1994 Immunohistochemical determination of in vivo distribution of Bax, a dominant inhibitor of Bcl-2. American Journal of Pathology 145 1323-1326.

Li L, Chen DB, Lin C, Cao K, Wan Y, Zhao XY, Nie CL, Yuan Z \& Wei YQ 2013 hPNAS-4 inhibits proliferation through $S$ phase arrest and apoptosis: underlying action mechanism in ovarian cancer cells. Apoptosis 18 467-479. (doi:10.1007/s10495-012-0797-z)

Martín V, Herrera F, Carrera-Gonzalez P, García-Santos G, Antolín I, Rodriguez-Blanco J \& Rodriguez C 2006 Intracellular signaling pathways involved in the cell growth inhibition of glioma cells by melatonin. Cancer Research 66 1081-1088. (doi:10.1158/0008-5472. CAN-05-2354)

Martín-Renedo J, Mauriz JL, Jorquera F, Ruiz-Andrés O, González P \& González-Gallego J 2008 Melatonin induces cell cycle arrest and apoptosis in hepatocarcinoma HepG2 cell line. Journal of Pineal Research 45 532-540. (doi:10.1111/j.1600-079X.2008.00641.x)

Mediavilla MD, Cos S \& Sánchez-Barceló EJ 1999 Melatonin increases p53 and p21WAF1 expression in MCF-7 human breast cancer cells in vitro. Life Sciences 65 415-420. (doi:10.1016/S0024-3205(99)00262-3) 
O'Driscoll L, Linehan R \& Clynes M 2003 Survivin: role in normal cells and in pathological conditions. Current Cancer Drug Targets 3 131-152. (doi:10.2174/1568009033482038)

Perdomo J, Cabrera J, Estévez F, Loro J, Reiter RJ \& Quintana J 2013 Melatonin induces apoptosis through a caspase-dependent but reactive oxygen species-independent mechanism in human leukemia Molt-3 cells. Journal of Pineal Research 55 195-206. (doi:10.1111/jpi.12062)

Reed JC 1997 Bcl-2 family proteins: regulators of apoptosis and chemoresistance in haematologic malignancies. Seminars in Hematology 34 9-19.

Reiter RJ 2004 Mechanisms of cancer inhibition by melatonin. Journal of Pineal Research 37 213-214. (doi:10.1111/j.1600-079X.2004.00165.x)

Rodriguez C, Martín V, Herrera F, García-Santos G, Rodriguez-Blanco J, Casado-Zapico S, Sánchez-Sánchez AM, Suárez S, Puente-Moncada N, Anítua MJ et al. 2013 Mechanisms involved in the pro-apoptotic effect of melatonin in cancer cells. International Journal of Molecular Sciences $\mathbf{1 4}$ 6597-6613. (doi:10.3390/ijms14046597)

Rubio S, Estévez F, Cabrera J, Reiter RJ, Loro J \& Quintana J 2007 Inhibition of proliferation and induction of apoptosis by melatonin in human myeloid HL 60 cells. Journal of Pineal Research 42 131-138. (doi:10.1111/j.1600-079X.2006.00392.x)

Salani R, Kurman RJ, Giuntoli R II, Gardner G, Bristow R, Wang TL \& Shih IM 2008 Assessment of TP53 mutation using purified tissue samples of ovarian serous carcinomas reveals a higher mutation rate than previously reported and does not correlate with drug resistance. International Journal of Gynecological Cancer 18 487-491. (doi:10.1111/ j.1525-1438.2007.01039.x)

Stehle JH, Saade A, Rawashdeh O, Ackermann K, Jilg A, Sebestény T \& Maronde E 2011 A survey of molecular details in the human pineal gland in the light of phylogeny, structure, function and chronobiological diseases. Journal of Pineal Research 51 17-43. (doi:10. 1111/j.1600-079X.2011.00856.x)

Trubiani O, Recchioni R, Moroni F, Pizzicannella J, Caputi S \& Di Primio R 2005 Melatonin provokes cell death in human B-lymphoma cells by mitochondrial-dependent apoptotic pathway activation. Journal of Pineal Research 39 425-431. (doi:10.1111/j.1600-079X.2005.00270.x)

Wong RS 2011 Apoptosis in cancer: from pathogenesis to treatment. Journal of Experimental \& Clinical Cancer Research 30 87. (doi:10.1186/ 1756-9966-30-87)

Wood PA, Yang X \& Hrushesky WJ 2009 Clock genes and cancer. Integrative Cancer Therapies 8 303-308. (doi:10.1177/1534735409355292)

Yang X, Wood PA, Oh EY, Du-Quiton J, Ansell CM \& Hrushesky WJ 2009 Down regulation of circadian clock gene Period 2 accelerates breast cancer growth by altering its daily growth rhythm. Breast Cancer Research and Treatment 117 423-431. (doi:10.1007/s10549-008-0133-z)

Yemelyanova A, Vang R, Kshirsagar M, Lu D, Marks MA, Shih IeM \& Kurman RJ 2011 Immunohistochemical staining patterns of p53 can serve as a surrogate marker for TP53 mutations in ovarian carcinoma: an immunohistochemical and nucleotide sequencing analysis. Modern Pathology 24 1248-1253. (doi:10.1038/modpathol.2011.85)

Zeng T, Zhang CL, Song FY, Zhao XL, Yu LH, Zhu ZP \& Xie KQ 2012 PI3K/AKT pathway activation was involved in acute ethanol-induced fatty liver in mice. Toxicology 296 56-66. (doi:10.1016/j.tox.2012. 03.005)

Zusman I, Gurevich P, Gurevich E \& Ben-Hur H 2001 The immune system, apoptosis and apoptosis-related proteins in human ovarian tumors (a review). International Journal of Oncology 185 965-972. (doi:10.3892/ijo.18.5.965)

Received in final form 24 September 2015

Accepted 9 November 2015

Made available online as an Accepted Preprint

10 November 2015
(C) 2016 Society for Endocrinology Printed in Great Britain 